\title{
The Reflections of Israeli Siege over Economic and Social Indices on Gaza Strip
}

\section{Abd EIRahman J AlFar ${ }^{*}$, Samir M Abu Mdallalah and Eman A ALkhoudary}

Department of Economics, University of Palestine , Al-Azhar University Gaza, Palestine

*Corresponding author: Abd EIRahman J AlFar, Department of Economics, Economics Lecturer, Al-Azhar University Gaza, Palestinian University, Palestine, Tel: +970-08-2641885; E-mail: a.alfar@live.com

Rec date: June 21, 2017, Acc date: July 10, 2017, Pub date: July 17, 2017

Copyright: (C) 2017 Alfar AEJ, et al. This is an open-access article distributed under the terms of the Creative Commons Attribution License, which permits unrestricted use, distribution, and reproduction in any medium, provided the original author and source are credited.

\begin{abstract}
Gaza's economy is still suffering from the Israeli blockade and the continued closure policy for a long time which have become more rigorous since 2000 and increased with the construction of the Apartheid wall in 2002 . After the Israeli retraction from Gaza in 2005, the economic conditions were exacerbated in which Israel continued control over the air, sea and land private sectors. Moreover, in 2007, the restrictions have increased and switched into expanded blockade separates Gaza strip from the outside world.

In spite of the mitigations that carried on during 2007-2015 period, represents in increasing the goods quantities which allowed to enter and exit from Gaza Strip for commercial purposes and the increasing number of Palestinians who are allowed to leave through Eretz crossing, the siege and its effects still exists till now.
\end{abstract}

Keywords Economics; Politics; Sectors; Goods; Territories; Natural resources; GDP; Customs

\section{Part 1: The Siege Concept, Mechanisms and Stages}

\section{The concept of siege}

Palestinian Central Bureau of Statistics defines the siege as: "the aggregate procedures imposed by the Israeli occupation authorities, which under its direct actions or influences causing a total or partial stops to the general movement and the movement of people and goods between communities in the Palestinian provinces, between the same provinces, between the Palestinian territory and the outside world and Israel on the other hand, including the difficulties caused by the partial or total stop to the movement of land crossings, sea or air" [1].

As noted from the definition, it focused only on the movement of people and goods. So it should distinguish here between the concepts of siege and closure, in which the siege is broader and wider than the closure that the closure is one of blockade mechanisms. In regard, the periods when the crossings were opened included many actions and complex restrictions that calls for Israel implementation, which leads to hindering the flow of goods to and from Gaza Strip. Thus, we agree with the overall concept that the blockade means "all actions and decisions taken by the Israeli authorities against the Palestinian territories and affect any economic activity" [2].

\section{The mechanisms of siege}

The most important mechanisms of the blockade followed by the Israeli occupation can be summed up in the following points:

A collection of procedures that formed the "quasi-Customs Union": were these procedures during the period of the occupation allowed moving goods and labors between the Palestinian and the Israeli economy under imposing non-reciprocal restrictions. However, the imports and exports are knuckle under complex measures as issuing import and export certificates through military orders, and imposing limits on the amounts and types of raw materials that allowed to enter the West Bank and Gaza Strip, and other actions. All these led to the emergence of unequal business relationships, pressure tax, regulatory restrictions and reduce the possibilities of access to the natural resources [3].

Formalize the "quasi-customs union" under the terms of Paris Economic Protocol, and in fact the Palestinian-Israeli economic relationship is far from being a customs union, as reinforced control and dependency relationships [4].

Frequent and inclusive closure: the blockade imposed by Israel on the Gaza Strip is a widespread blockade (land, air, sea), where Egypt controls one crossing, Israel controls the other crossings, which undergo to Israel closure policy for goods, services and the movement of people [5]. In addition to the construction of the apartheid wall, that led to the segmentation of west bank and Gaza strip economic, and reducing the production capacity and capabilities in them [6]. Moreover, it closed the commercial crossings against import and export movement, and prevented the entry of the necessary raw materials for industry or construction sector [7].

Reducing the amounts of petrol, diesel, cooking gas and industrial fuel used in operating the only power plant on the strip (OCHA, 2009, p. 2), and this reduction in quantities has led to a permanent shortage of electricity, which has had a negative impact on the population lives and the function of water and sanitation systems, health and infrastructure devices at all [8].

Restrictions on transfers the funds to Gaza strip banks, and ban the entry of the shekel and other currencies with Israeli banks [9].

Revocation on Gaza Strip Customs Code [7]. A tangible reduction to the fishing areas and agricultural land that Palestinians can be accessed [9]. It is estimated about $35 \%$ of the restricted border land, is arable land [10]. 
The economy suffocation process policy on the strip included razing agricultural land and destroying the agricultural property. And create a distorted reality for the agricultural sector unable to achieve any development or growth, also destroying the agricultural constructions and agricultural irrigation networks and water pumps, etc., as well as to impose severe restrictions on the supply of the agricultural sector's needs of raw materials and agricultural equipment [11].

Freeze the transfer of what is known "clearance revenues" that is taxes owed to the Palestinian Authority and that Israel collects on her behalf [6], accounting for about $70.8 \%$ of the local revenue of the authority during the year 2015 revenues [12].

Prevent the entry of tens of goods under the name of "dual-use goods," arguing they can be used for acts of resistance, which is often used in the construction industry and other various economic activities [13].

\section{Stages and developments}

\section{A) The siege from June, 2000 to June, 2007}

After 1967, the occupation authorities exert a huge effort to adjust the Palestinian productive structures to suit various Israeli economic policies, where the Palestinian economy has become a dependent economy and submissive to the requirements of the most sophisticated Israeli market. In addition to that, the Paris economic agreement and its attached protocols has provided many features for Israel to have the ability to control the market and Palestinian trade, which prevented any achievement on real economic growth or development [14].

During the early years of receiving a weak follower economic, the Palestinian authorities tried to uphold it but quickly the Palestinian life deteriorate generally and the economic specially. As a result to the Intifada in the last quarter of 2000 , the Palestinian territories faced a harsh siege and closure since 1967 who revealed on the status of Palestinian economic vulnerability and inability to hold out against the Israeli blockade. All this is due to the overall dependency in all commercial and financial policies and financial and thus development policies, where Israel has imposed inclusive and internally closure work on separating it from the outside world, the separation of the West Bank from the Gaza Strip and Jerusalem, and the imposition of restrictions on the movement of people and goods and the circulation of principal. However, this have a negative impact on various economic sectors of the West Bank and Gaza such as stopping trading and wounding of all economic sectors and productivity to a complete standstill [15]. The period between September 2000 and mid-July 2007 is considered the most difficult years when compared with previous ones, in which the days of the commercial crossings closure reached 769 days during the period from 2000 to 2006 [4].

The GDP achieved a big decline in 2000 during the intifada years to reach 1134.8 million dollars in 2002 compared to 1469.6 million dollars in 1999, the pre-Intifada, that means the output fell about $22.78 \%$.

The unemployment rate in the Gaza strip fluctuating rising and falling, where it achieved its heights rate during 2000-2006 period which was approximately $37.9 \%$ specially in 2002 , and achieved the lowest level to reach $34.6 \%$ in 2006 [15].

As well as poverty in the strip rates, has increasing to reach its highest rate in 2002 of about $68 \%$ compared to $32 \%$ in 1999 so it rose $112.3 \%$ nearly, then took to whiffle up to $30 \%$ in 2006 [16].
In addition, there are more results to the siege beside all previous things, such as: the deterioration in overall economic sectors, private investments and others, due to the procedures and the blockade adopted policies by the occupation that prevented the arrival of raw materials and necessary tools for the work of the various sectors, as well as Shoveling the agricultural land and control over water resources, economic and others.

B) The inclusive siege during June, 2007

Because of Hamas takeover of Gaza strip, the year of 2007 was a turning point in which the restriction increased to turn into a complete blocked that isolates Gaza strip from outside world. In 19 September, 2007, Gaza strip was considered as a hostile entity, where Israel closed all border crossings towards the people and goods movements. However, the procedure did not stop at this point, it also affected the Gazan's needs of gas, fuel and construction materials for various economic sectors; the agricultural, industrial, building, construction, transport sectors and etc., causing a complete stagnation in the economic sector.

As a result of nine years of economic blockade and three military operations during the seven years, a massive destruction was appended the Gazan's economy. For instance, a destruction on the infrastructure, resources and productivity base. The influence on the agricultural, industrial and commercial facilities and others. Rising the unemployment and poverty rates and stopping the production operations on a large scale. Beside a lot of negative effects that reflected harmfully on the various economic and social indicators, which predetermined to paused on it and review.

\section{Part 2: The Economic Indicators}

\section{Agricultural sector}

The agricultural sector is one of the most important productive economic sectors in the Palestinian economy that plays a significant role in Participating to the gross domestic product and labor absorption, but in spite of this, it does not have the essential attention and does not do its role in the economy as a result of the great challenges which faced it.

Therefore, during the period of 2007-2014 the contribution of the agricultural sector in GDP in Gaza did not exceed $11 \%$, but fell to $5.2 \%$ in 2014 according to reviewing the statistics published in the Palestinian Central Bureau of Statistics this demonstrates the poorness of this sector, the carelessness on it, the weakness of its contribution to the GDP and of the productive base and the Israeli policies the attacks against the Gaza Strip; in addition to, the losses that caused by the military aggression against Gaza strip, in terms of a report said by the UNCTAD that in the recent military operation in July 2014, the total damage to agriculture is estimated at $\$ 550$ million, 220 wells farm were destroyed or had serious damage, and not less than 4000 workman in the agriculture sector affected by the damage to agricultural land [17].

Moreover, we cannot ignored that the blockade had a negative impact on this sector; here are a variety of effects associated with the blockade, which was worked on falling the participation of the agricultural sector deeply in Gaza's economy generally:

The corrosion of the productive base and the destruction of infrastructure because of the imposition of the inclusive blockade and preventing farmers from reaching their lands and natural resources. According to a report by the UNCTAD in 2012, the Palestinian 
territories are now working at less than two-thirds of physical capital in 1998.

The requisition of the agricultural land and the financial resources, and the imposition of the restrictions on the movement of labor has led to overall shift towards the services sector as an alternative source to run.

The chance of this sector in obtaining the necessary funding was decreased, due to the donor's treatment to the agricultural sector as a fragile one [13].

The blockade limits the entry of production inputs for cultivation as seeds, fertilizers and pesticides, also, equipment and machinery [18].

The loss to the agricultural sector due to the restrictions on the movement of Palestinian people and goods, as it prevented the farmers to access to their lands for running their works and marketing, import and export the agricultural products and inputs.

The negative impact of the blockade on the spoiled and limited validity of the agricultural products, and control over water resources, which caused increasing in the production costs and corrosion of Palestinian producers profits due to the incapability of their products to compete with Israeli counterparts [19].

The fading of productivity due to the imposed restrictions on the imported inputs and the failure of ensuring credit

A large decline in fishing, in which the fishing are not allowed alongside the coast of Gaza, except along 3 miles only and increased since 2012 to six nautical miles instead of the 20-mile prescribed in Paris economic agreement. Where specifying the narrow distance cause a depletion and lessening in the fishing activities revenue.

The high rates of unemployment that the agricultural sector is no longer able to assimilate the labor, where the operations of the internal and external closures and the loss of fertile land and the inability to reach the rest of the agricultural land has trimmed the capability of this sector to provide part-time jobs with low-productivity as it was before the blockade [20].

Thus, the restrictions on the Gaza Strip by the occupation must be removed, especially on the agricultural sector, and providing opportunities to be allowed to access the agricultural land, markets and water resources, in addition to the need to improve and develop the infrastructure and increased investment in the basic infrastructure, as well as the role of the Palestinian Authority in the need to take penitentiary actions and increase the share of this sector in the budget and increase the funding from the donor nations to it, in order to renew the agricultural sector and improve its contribution rates in GDP as well as increase its role in reducing unemployment rates.

\section{The industrial sector}

The industrial sector is one of the important productive sectors of the economy that have an active role in attaining economic growth and development, also it has a role in reducing unemployment rates and improving the balance of trade. Moreover, the data published in the Palestinian Central Bureau of statics show the pathetic role of the industrial sector in participating to the gross domestic product in Gaza.

As we notice that there is decreasing in Value Added to the industrial sector since 2006, where it decreased $35.4 \%$ compared to 2005, and about $53.4 \%$ in 2007 compared to the same year, in addition that the highest contribution rate of the industrial sector in GDP in the Gaza Strip record in 2010 and it was about $12.6 \%$, and 2004 recorded the lower rate, which stood at $8.7 \%$ because of the recent military aggression in the Gaza Strip. Thus, this sector also does not have the needed attention and affected by the Israeli military operations and policies of siege, restrictions and the destruction of the industrial facilities, the infrastructure, the productivity and the interest base. As well the beginning of the siege in 2007, approximately $90 \%$ from 3900 industrial facilities in Gaza closed and stopped working permanently or temporarily. Because of not exporting any industrial product since that time, the industrial sector employed less than 3000 worker or approximately $9 \%$ in 2007 compared with 35000 worker before this year (UNCTAD 1, 2012, p. 22), also this sector in the recent attack on the Gaza strip had a serious damage estimated at $200 \$$ million [21].

Therefore, the siege and the occupation's Policies have many negative effects on the industrial sector in Gaza which led to its decline, through [19].

Restricting the development of industry by identifying the types and the amounts of raw materials which are allowed to enter the Palestinian areas to be used in manufacturing.

Israeli restrictions on Palestinian exports and imports such as the complex procedures which required for the certifications.

Destroying many of the crops and the production base, which caused losses for the industrial activities and led to significant deterioration especially in industries which depends on the agricultural products as inputs for production process

Lack of access to the inputs that needed for production, as well as to foreign markets and the markets of the West Bank

The dumping policy followed by Israel in the Palestinian market which was flooded by Israeli-made goods of low price and quality, which led to inability to establish any Palestinian industry that is able to compete rival Israel's projects.

Donors' focus on financial support for emergency and relief aid, without paying attention to infrastructure and production sectors

Reducing the amounts of energy supplied to Gaza Strip, resulted in increased costs for the owners of various industries [22].

Therefore, the elimination of the restrictions and the imposed blocked on the Gaza strip will stop the deteriorating of the infrastructure and reconstruct it, increasing the industrial sector productivity and increasing its capacity for labor and its positive reflection on lessening the unemployment rates. Also, importing the modern machinery and obtaining the raw materials easily, as well as attracting the foreign investment and encourage the domestic ones toward the industrial sector, and increasing the rate of export products and its positive impact on improving the balance of trade.

\section{The GDP per capita}

The GDP in Gaza Strip witnessed many hesitations on the impact of several features and the most important one is the inclusive blockade imposed by Israel on Gaza Strip in 2007. The one who follows the statics finds that due to the second intifada and the collective sanctions policy that the occupation follows, the growth of the GDP and per capita has been decreasing during 2000-2002 then has been flourished to reach 1792.9 million dollar in 2005 , which did not last long. 
Then, again, the GDP and per capita has fallen from 2006 to 2008 because of the inclusive blockade on the Gaza strip, and the rate of decline in the growth of GDP was around $11 \%$, and the rate of decline in GDP per capita was $14 \%$ during that period. Moreover, in 2009 the GDP and per capita had increased but stay less than its previous levels. It continued to boost and flourished until the GDP reached 2012.7 million dollars in 2013, this was the highest value reached by 2000-2015, and meanwhile, the value of the portion per capita in 2013 is about $\$ 1182.9$, the highest value since the imposition of the inclusive siege in 2007.

This is due to projects funding's from donors but this did not still long according to the rareness of inputs and the occupation targeting to the tunnels economy, Which led to a standstill in the activity of construction and transport sectors. Because of Israel military operation on the Gaza Strip in 2014, the GDP growth rate decline about $15.1 \%$ and the growth rate per capita about $18 \%$ over the previous year, which resulted in a stagnation case within the economy and we pointed here that 2015 has achieved a GDP growth rate of $7 \%$, but lower than the previous level.

So, the GDP growth considered as being fluctuating and unsettled during the period under study, as it depends on the political events and donor support, which is beyond the control of the Palestinian Authority and difficult to predict. And therefore, the siege has had a negative impact on GDP growth, as it has recorded a negative growth rates in the several years since the blockade, and the years that have achieved increasing in the GDP growth was characterized by declining and it is less than the previous level compared with pre-blockade, which also applies to per capita GDP.

\section{Foreign trade}

Before 2007s siege, the volume of exports was more than 15,000 truck in 2000. But after a siege in 2000, Israel has prevented exports and imposed severe restrictions on trade with the West which have led to stop the exports from Gaza almost completely. Adding, in 2010 the number of entering trucks which loaded with imports was 720 truck or about $23 \%$ per week from the total trucks before the blockade [22], and in 2013 did not issue except a load of 182 trucks from the agricultural crop [23].

Here for the first time since the imposition of the siege in 2007, Israel allowed in 2015 the export of goods from the Gaza Strip into Israel, also it has allowed export limited quantities before this especially after partial mitigation of the blockade in 2011. In addition, the rate of exports from the Gaza Strip has risen about six times compared to 2014 but at the same time these exports does not account for only $14.5 \%$ of the sector's exports in 2005 [23].

Therefore, the foreign trade affected negatively by the blockade, in which caused a decline in business activities within the Palestinian areas, and these effects can be summarized in the following points:

Israel has imposed restrictions on the Gaza Strip imports, but it do not allow importing except a limited quantities of 67 product compared to 4000 product before the blockade, and the most are basic food items, and health and hygiene needs, which are about $60-70 \%$ of these imports.

The exports are limited to a small range of products such as flowers and roses [22].
Isolating Gaza from the world and its traditional markets in the West Bank and Israel, which were enthralled about $85 \%$ of its exports before the blockade [17].

Tightening restrictions on the movement suddenly.

A negative impact on the trade balance, where exports are falling down greater than imports.

The use of production factors less than its capacity as a result of the barriers that interrupt the movement of these factors, the high cost and tightening the institutional and regulatory constraints [13].

The lacking of the strip exports that have low value added in competitiveness due to the continuing of blockade.

The inability to obtain inputs and high costing in production and transportation.

Reserve all imported goods to the Palestinian Authority at ports and border crossings, resulting in the payment of high fees and fines [24].

From the importance of the foreign trade sector, the need to eliminate the siege and the restrictions appears, as the foreign trade has a pivotal role in the Palestinian economy which cannot be accomplished in light of the restrictions and the ongoing situation. whereas the foreign trade linked to the labor market and productive economic sectors, the agricultural and the industrial sectors which has an essential role in providing the needs of the local market of consumables and production needs and marketing products and other.

\section{Public finance}

It's well-known that the Palestinian budget was and still suffering from the lack of income needed to cover the expenses which put it in a case of a semi-permanent deficit. Therefore, the siege affected the public finance of the Palestinian Authority and deepened its crisis as the imposed siege on Gaza strip had affected the strip contribution in PA's budget. In 2013, The Strip had a $3 \%$ contribution in enhancing PA's revenues, while he had received about 43 percent of public expenditures. In addition, as a result of the complete siege and the policy of not transferring the taxes collected by Israel on behalf of PA, the incomes were characterized by Volatility and irregularity as it was detained for political reasons. And thus, Israel's control of these incomes, as a form of siege, had negative effects represented by depriving the Palestinian economy from what could have been contributed by these incomes in investing and achieving economic growth and development [19]. The lifting of the siege on Gaza will lead to ease the financial pressure on both sides of the Palestinian public budget, as it will, on one hand, increase the contribution of Gaza Strip in the public income of PA, and control the expenditures directed to Gaza Strip on another hand.

\section{Reconstruction}

The siege, also, has an effect on the Gaza strip reconstruction process, where it slowing down the process of reconstruction. In addition, the imperfect support by donors is another effective factor in the reconstruction process, where only paid $27 \%$ of the amounts that had to paid, in the middle of the month of May 2015. As well as the blockade prevented the entry of construction materials that needed for this process [17]. Furthermore, the inability of the consensus government to take over its governmental duties effectively in the strip, and importantly to say that until the end of 2015 only $15 \%$ of the 
displaced families internally were not able to return to their homes [23].

Thus, the Palestinian public financial prospects become dim as a result of Israeli military attacks on the Gaza Strip, which led to a widespread destruction reach the infrastructure, productive capacity, livelihoods and human capital. Moreover, it should marked a huge sums of money from local and foreign aid resources to rebuild the strip in order to retrieve the economy to his condition that was originally weak. That must consist with the authority's efforts to work on financial controls and implement reforms that can do in lifting restrictions [20].

Even the reconstruction process will not leave that great positive impact on the economy, as in shade of undergo economy to the siege and inclusive closure and characterized by corrosion of the productive base, the pumping of funds to increase the finance in the domestic demand towards this economy will increase the imports not the domestic production.

In case of pumping funds for reconstruction and economic rehabilitation, the negative impact of the siege will remain on overwhelming of any positive effect on the economy, and the most influence will reflect on the increasing of imports, which are imported in large amount from Israel [22].

Hence, the lifting of the imposed blockade on the Gaza Strip to begin the process of reconstruction and the continuation of economic activities is necessary to reduce the high deficit and to ensure that the financial Palestinian Authority is out of this crisis.

\section{The investments}

Gross fixed capital formation is as other economic indicators that affected by the Intifada, the procedures followed by the occupation and the collective punishment policy. As well as it affected adversely in 2007, where the Palestinian gross fixed capital formation has achieved a negative growth at this year and declined by $22 \%$ compared to 2006 's year. The reasons of that negative growth returned to the imposition of Israel's inclusive blockade policy and the following measures that caused destruction in the infrastructure, agricultural lands and other, which reduces the investment incentive for investors and the capital outflow abroad.

Furthermore, in the Gaza Strip, the Gross capital formation in 2009 reached 46.4 million dollars, and flourished again due of the revival of the construction sector. Then, it decreased to 100.9 million dollar in 2013, and was in 2014-2015 nearly about -209.6 and -39.2 respectively because of the ongoing imposed blockade on the strip and the recent Israeli military operation in the Gaza Strip [25]. So, the effects of the siege on the Gaza investments can summed up in the following points:

Increased costs on the emerging dealings because of the imposed restrictions on the Palestinian access to the local and international markets.

Shifted many of investment activities away from agriculture and industry in the direction of non-tradable goods sector [22].

Hitting the investments projects in total stagnation state, that resulting in the outflow of domestic funds to neighboring countries seeking for stability [26].

So, in order to achieve a state of flourishing in the public and private investments sector, the imposed restrictions on the movement of goods and labor must be removed, and reconstruct the infrastructure and the
Palestinian productive base in general. Also, eliminating the danger of returning to restrictions has a positive impact on attracting and encouraging investments in the public and private sectors.

\section{The banking sector}

We mentioned previously that from the siege mechanisms, Israel has imposed restrictions on transferring funds to the Gaza Strip banks and banned the entry of the shekel and other currencies. Also, the restrictions imposed on cash transferring to the Gaza Strip caused actual stagnation to the banking system, resulting severe damage to the economy. So, we can summed up the effects of the siege on the banking sector in the following points:

Stifle the foreign trade, in which complexes the process of daily exchange of goods and services and increases transaction costs.

Undermine confidence in banks and shifting the financial activities in informal and unorganized channels [20].

Weaken the efficiency and profitability of the banking sector and increase the risks that faced it [22].

Decreasing PMA's efforts in combating the money laundering [9].

Thus, the siege was an obstacle to the foreign and domestic trade in the Strip, which reflected adversely on the banking sector activity and the work on guiding the economic financial activities towards the informal sector which supervised by the Palestinian Monetary Authority. So, it must work on removing this imposed restriction by Israel in order to stirring the economy and development in the Gaza Strip. Moreover, we cannot Condon the positive role of the banking sector to renew Gaza's economy.

\section{The infrastructure}

The infrastructure in the economic field defines as all services and facilities that have a direct or indirect effect on the economic and commercial life, including the power grid, water and sanitation, which we will focus on, telecommunications networks and Internet and ecommerce services, roads network and traffic, ports, border crossings, airports transportation, construction of industrial cities and free zones trade, economic and trade agreements and the Legislation of laws, administrative, financial and legal systems [27].

Here are the most important reflected effects of the blockade on the infrastructure:

According to Oslo Agreement, the Palestinian energy sector is largely depend on imports energy from Israel. In 2013, the Palestinian territories has imported electricity from Israel at a cost of $\$ 660$ million, also, Israel has supplied the Gaza Strip 63\% of its consumption of electricity and the power plant in Gaza has saved 26\% and \% in Egypt of its consumption in the same year [17].

In 2010, Israel's banning of importing the oil and diesel for commercial purposes has led to a lack of fuel imports to cover all the necessities of the power plant, as it does not cover except $33-46 \%$ of Gaza's power plant needs, which affected the hours of electricity connections, furthermore, the imports of cooking gas does not cover except $66 \%$ of the basic needs.

The Shortage of energy caused by the blockade has led to cost the owners of industries and service providers costs up to $50 \%$ of their limited income in 2010 [22]. 
The deterioration of water infrastructure especially sanitation due to lack of proper maintenance and the appropriate update for infrastructure, in addition to, discharge a large amount of ongoing treated water in the environment, resulted in increasing the pollution of the sea and underground rocky layer causing serious health problems.

The siege caused a limited availability of construction resources and structural parts, and preventing running on and the maintenance of infrastructure related to water and sanitation [9].

$20-30 \%$ of the water and sanitation systems in the Gaza Strip affected by the recent military operation on the strip [17].

The blockade led to continuous deterioration of water quality in the strip, as it destroy the basic infrastructure of water during the Israeli military operations in the Gaza Strip, and the continuation of this siege prevent rebuild process [12].

Consequently, the elimination of the siege and develop and modernize and construct Palestinian infrastructure in the Gaza Strip particularly, will increase the volume of investments. As it stimulate the local investment and catch the foreign investments in industrial and trade factors and other services. Moreover, it will lead to the elevation of foreign trade sector, as well as enhance the quality of the Palestinians citizens' life.

\section{Food insecurity}

The continuation of the siege and the low per capita GDP and high unemployment rates subjected a wide class of the Palestinian people to poverty and food insecurity which is represented by people's inability to access to safe, nutritious and socially acceptable foods in order to maintain a healthy and productive life. International reports have showed that about $75 \%$ of the population of the Gaza Strip have suffered in 2009 from food insecurity (OCHA, 2009, p. 3) in 2010, 52\% of The Strip families have suffer from food insecurity, and about $13 \%$ others were at the risk of food insecurity [28]. In 2013, food insecurity was already high even before the military operation on the Gaza Strip in 2014. It is worth to mention here that the conditions in the Gaza Strip regarding food insecurity are worse than those in the West Bank, as six out of every ten families don't have food insecurity in Gaza Strip, compared to one out of every five families in the West Bank. Food insecurity now affects $72 \%$ of households. As a result, most of the population is forced to rely on aid to cover its basic needs, as the number of refugees relying on UNRWA food (UNRWA) has risen from 72,000 in 2000 to 868,000 by May 2015 [17].

The reasons for the increasing food insecurity are the siege imposed by the occupation, which left a negative impact on unemployment and poverty rates in the Strip, as well as the destructive policies of occupation, particularly of agricultural assets, and the inflation of basic food prices.

Therefore, we call for implementing agricultural development, promoting of agricultural production and food consumption patterns, taking the necessary measures to provide for the needs of families in prices that with prevailing living conditions, and seeking to remove restrictions that prevent commercial flow of goods, in order to ensure food security in Palestine as a whole.

\section{The economy of tunnels and its repercussions}

The tunnels economy appears to alleviate the effects of the siege, which has reached the peak within 2007-2013 period, in terms of a 1532 tunnel under the ground between Gaza and Egypt widening 12 kilometers. Also, it mentioned that the tunnels are informal and out of control of both governments on both sides of the border and it cannot be considered as an unorganized secret economy.

During its flourishing period between 2007-2013, this tunnels has allowed importing a collection of products which Israel has imposed restrictions on its importing such as the imports of fuel and gas, cement, building materials, raw materials, seeds, fertilizers, agricultural tools, preservatives materials, packaging and spare parts [17], and about two-third of the economic activity was directed toward the importation of these goods. Furthermore, the tunnels economy is risky that can threatening the life. Many of Palestinians have been killed or injured in various occurrences of tunnels collapses or Israeli air strikes [22].

It's true that working in the tunnels had been stop in 2013, but it led to a decrease in the inflation rate in the Gaza Strip in 2011, for example, because of the availability of imported products through the tunnels. whereas the food coming to Gaza from Egypt, although its high transport costs, it is considered cheaper than those imported from Israel between $10 \%$ and $15 \%$ [23].

Moreover, there are many negatives linked with the tunnels, for example, it turned The Gaza strip to a consumer market only and put it in a monetary crisis due to the export of money and the import of goods, it raising the prices of smuggled goods and materials, sanctified the Strip isolation from the outside world, and deepened the division and political separation from the West Bank and other [26].

Hence, it is true that the tunnels have delivered certain goods were not available or restricted by the occupation before the existence of the tunnels, but it not substitute tocontinue the movement of goods through the official crossings, as it could not made a change in the export sector or even to provide the Gaza Strip by the required level of the various imports which are necessary to the process of rebuilding its productive economy.

\section{Part 3: The Social Indicators}

\section{Unemployment}

Anyone followed the progress of the unemployment rate in the Gaza Strip find that after it recorded low rate up to $18.9 \%$ in 2000 , it did not return to that level until now. Thereafter, it rising to $100.5 \%$ in 2002 and reached $37.9 \%$ due to the second intifada, the occupation procedures and the policies of collective punishment followed by Israel, which has doubled the unemployment rate. Moreover, the highest level in later years has been achieved in 2008 to reach $40.6 \%$ because of the inclusive Israeli siege and preventing the individuals and workers movement to Israel, and by this it increased to $115 \%$ compared to 2000 , and about $37 \%$ compared to 2007 . Mentioned that the decline in the unemployment rate in the later years refer to the construction sector revival and easiness of the restrictions. But the rise still dominant at this rate until it reached the highest rate during the period 2000-2015, which was about $43.9 \%$ in 2014 due to stifling the strip, the recent military operation against it, slowing down in the tunnels economy and demise the activity of transport and construction 
sectors. Also, it dropped slightly in 2015 to up to $41 \%$ due to the easing policy followed by Israel [15].

In fact, the unemployment rate was deepened because of the imposed restrictions on the labor movement, reallocate the capital between Gaza strip and West Bank, the low levels of the private investments that could absorb a good part of the labor, the imposed restrictions on the import and export movement that also has a role, where the exports completely banned and the imports facing severe constraints on the import of construction materials and other [29]. However, the evaluations indicate that it is necessary to achieve annual growth in the GDP about $4.5 \%$ to accommodate the new entrants to the labor market. So, it must lifting the Israeli restrictions, and access more to the economic and natural resources, in order to overcome the unemployment crisis, because the elimination of the blockade will lead to [23].

Increasing the investment in the productive capacity and increasing the private sectors' ability to create jobs.

Correcting the malformation in the investment patterns, as it is biased to the service sector at the expense of the productive sectors that distinguished by its intensive labor [30].

We agree with what mentioned previously about that the siege have a negative impact on the unemployment rate, and about the effect of eliminating the blockade on the unemployment rates in the strip, adding that the blockade is the basic and the major cause

\section{Poverty}

The Palestinian territories is characterized by its height poverty rates, and this proportions in the Gaza Strip varied than in the West Bank because of the different political factors and the Israeli collective sanctions and other. By reviewing the statistics of poverty rate in the Gaza Strip, which it is not available for all years in the Palestinian Central Bureau of Statistics, we find that the poverty rate during the period 2009-2011 did not fall below 38\%, which is higher nearly $15.15 \%$ compared to 1998 , In addition, the average poverty rate during this period reached $38.36 \%$, and the following years saw instability in the poverty rate up and down, but it did not return back to its previous levels, which emphasizes the severity of the poverty problem in the Gaza Strip [31].

Thus, the blockade had had a negative impact on the living standards in the Gaza Strip that it raise the poverty level and keep it high, due to the following reasons [13]:

Instability and decline the economic activity.

Low wages levels for workers.

The loss of jobs as a result of Israeli restrictions.

Decrease in operating capacities for the public and private sectors.

Denial of access to the Palestinian natural resources.

Hence, the negative impact of the siege cannot be ignored on the living standards and raise poverty rates, which requires the removal of the restrictions imposed by the occupation in order to be able to achieve an inclusive economic development, and create a productive Palestinian economy provides that provide its members of their minimum needs reflected in a positive impact on the living standards and improve it and reduce the severity of the poverty problem.

\section{Women affairs}

The degradation which resulted from blockade affected the Palestinian woman in Gaza Strip. In fact, her conditions deteriorated in all different aspect of life and her burdens increased. In addition, the blockade affected on the economic role of women and her participation in the labor market. When we review the statistics of women unemployment rate among women participating in the labor force for individuals (15 years and over) in Gaza Strip, we can see that it's increasing in most years during the period 2000-2015. Also, the years which achieved decreasing in its rates are considered as nothing compared with other years. After imposing the total blockade on Gaza strip, we can see that women unemployment average jumped from $29.7 \%$ in 2007 to $42.8 \%$ in 2008 so it's about $44 \%$. We have also to mention that the rate of women unemployment increased after this in most of the year until it reached a high rate which is considered the highest during the period 2000-2015 and this is estimated by about $60 \%$ in 2015 [16].

Moreover with the ongoing siege and the cut of salaries, the weakness start to affect the strength of the Palestinian families, and the extreme poverty affect new Palestinian in the community. Also, the increase of the Palestinian families created a huge burden over women.

According to this circumstances, the effects of the inclusive blockade over women summed up in the following:

The women's seeking for ways to ease this suffocating crisis.

The negative impact on social family relations as a result of the cut of salaries and the accumulation of debt.

The negative impact of women's relationship with their children and husbands, in addition to that some families prefer teen marriage in order to decrease their expenses over them, indeed some men seek a productive women rather than a house wife [31].

The deterioration of the living, psychological, social and economic status of women in addition to increase the onus on her [32].

Increasing violence against women in which the blockade led the Gazan's families to adopt appropriate mechanisms with multiple crises such as electricity cut, water pollution and decrease fuel, which put pressure on a number of relationships within these families [33].

The participation of women concentrated in the informal sector and small scale in the formal sector, due to the structural distortions suffered by the Palestinian economy as a whole [23].

$75 \%$ of students suffer from a lack of focus because of the worries associated with the blockade and division [34].

Through what mentioned before, the reality and women's suffering in the light of prevailing circumstances in the Gaza Strip become clearer. Because of the market situation and its permanent suffering from the crisis, the role of women in economic activity has diminished. Therefore, it must exerted a huge effort to enable women to participate in the economic activity, increase their role to benefit of them as a human source in the community development process and to increase awareness and provide protection towards violence against women, as well as the need for gender equality.

\section{Health}

The Siege does a destruction and weakness in the health infrastructure such as the materials and medical supplies of medicines 
and equipment's, in addition to the weakness of potential due to the siege and the military aggression, also. Where a study reported that in the recent attack in 2014 in the Gaza Strip 15 hospitals and 45 health care center were damaged [17], which making the health sector unable to provide the vital and medical services as required.

Hence, the effects of the inclusive siege on the health sector can be limit in the following points [35].

Maintenance and repair works at the various health facilities were affected, due to not entering of the basic building materials that are necessary for the process of reconstruction and development.

Depriving patients of treatment opportunities in abroad and entree to the hospitals outside the Gaza Strip, due to the restrictions and complications on the procedure by the occupation.

The Shortages in electricity hour's connections associated with reducing of the imported Fuel from Israel to rely on the generators in hospitals and health centers, where the Ministry of Health reported that it was consumed about 700 thousand liters per month in 2014, in addition to the risk of generators and lack of spare parts that are necessary to it.

Depriving patients of surgical and diagnostic services for dozens of medical delegations from various countries around the world.

Some of medicines were finished and pharmaceutical stocks were declined. Where in 2013 the pharmaceutical stocks have fallen about $30 \%$, and about 460 class of medical consumables finished in the same year, and in 2014 about $28 \%$ of the essential medicines list finished, also.

Hence, the blockade leave a health system full of challenges characterized by weakness and lack of facilities, medical equipment's and medicines, and not to mention the hard, unsafe and nonguaranteed process that must be crossed by the patients in need of special treatment outside the Gaza Strip to obtain permits to leave, and stop the construction or the development of the hospitals. As well as, the electricity crises and its negative effect on patients and the health sector totally. Therefore, there is no doubt that the elimination of the siege and the imposed restrictions on the strip will be reflected positively on the health system work and raise its level.

\section{Education}

The policy of the inclusive blockade and the Israeli military attacks reflected negatively on the Gaza strip. Where it had an effect on the students, the educational institutions and even teaching staff. As an example of the Israeli military operation in 2014 which was the most violent one against the strip, 26 school damaged completely and 112 school damaged partially. In addition to what we mentioned previously, the reconstruction process did not take its right path until this moment because the siege has affected and deepened the negative effects on educational sector in the Gaza Strip [17].

So, the effects of the blockade on the educational sector can be summed up in the following points [36].

The negative impact on higher education institutions of its various sectors of teaching staff and students.

Isolate the educational institutions in the Gaza Strip from its counterparts in the Arab and foreign countries, and lowering participation in the Arab and international conferences and even the regional ones.
The retreat of scientific research and the weakness of providing the universities libraries by the necessary resources and references for the scientific research and teaching.

Not allowing the chemicals and other materials to enter that are necessary for scientific laboratories in higher education institutions.

A lack in student's educational achievement and, lack of concentration and difficulty in organizing the time due to continued power cut.

A decline in funding that is directed towards the educational sector, which effect negatively on the development of the infrastructure of the higher education institutions.

Preventing most of the students to go to universities outside the Gaza Strip, because of the severe restrictions by Israel on whether to allow the granting of licenses to get out of Gaza, in addition to the holes of the Rafah crossing [9]. In 2015, Rafah crossing was opened 32 days only [23].

Therefore, the siege imposed on the Gaza Strip should be eliminate in order to providing sufficient support to various institutions of education, providing construction and reconstruction to the destroyed schools and improve its infrastructure, enhancing the communication between the Palestinian educational institutions and its counterpart in the Arab and foreign countries, as well as, facilitating the procedures for students who wishing to study abroad [37-39]. In general, the educational programs should be develop and linking the education with the requirements of society and the labor market and improving the professional development, in order to strengthen the human capital and reduction the graduates unemployment rates.

\section{Part 4: Results and Recommendations}

\section{Results}

The policy followed by the occupation that represented in closure and blockade have led to a deterioration in the Palestinian living conditions.

The siege imposed on the Gaza Strip stop the majority of economic and business activity.

The siege leave a negative impact on GDP and per capita, as well as the productive sectors and the infrastructure.

The Israeli blockade increased the Gaza Strip depending on aid to safe livelihoods.

The imposition of restrictions on the movement of goods has led to a weakening of the export sector in the Gaza Strip.

The continued existence of the siege of the Gaza Strip prevent achieving the reconstruction, and worked on declining the development in the Gaza Strip.

The unemployment rates and poverty for the Gaza Strip were affected by the Israeli blockade where it increased and exacerbated it, and decline the level of education and health.

\section{Recommendations}

Take the essential steps to break the strict siege imposed on the Gaza Strip. 
The need to empower the officials for designing the Palestinian public policy and to use the full economic policy tools in order to put the Palestinian economic on the recovery and continued growth path.

The need for a unified government in the West Bank and the Gaza Strip in order to establish bilateral partnerships and multi with the donors to reconstructing and lifting the siege and re-structures the infrastructure in the Gaza Strip.

Exert regional and serious efforts to modernize the procedures at crossings border and unified the legal and technical aspects for the customs dues in order to create an efficient transport system to serve the regional business activities.

It must exert efforts aimed to re-establish the trade and production networks between the West Bank and Gaza Strip.

The mobility and transit agreement that signed with Israel in 2005.

Allow the Palestinian Authority to make use and develop the natural gas fields in order to solve the energy sector crisis.

Make a necessary efforts for women's empowerment and gender equality.

\section{References}

1. A survey of poverty in the Palestinian territories report the main results. The Palestinian Central Bureau of Statistics.

2. Mazen Al-Egla (2011) The siege of the beleaguered "Evolution of the closure of commercial crossings, the Gaza Strip and its aftermath policy". Readings strategy Palestinian Planning Center.

3. The Palestinian war-torn economy: aid, development and state formation United Nations Conference on Trade and Development United Nations.

4. Mazen Al-Egla (2011) The future development under the blockade. The magazine of the Palestinian Planning Center.

5. Agricultural Development Association PARC, the legal dimension of the Israeli blockade on the Gaza Strip, A special bulletin, Towards a better future of civil society in Palestine through wider participation in the areas of public life. Spanish Cooperation Foundation "AECID".

6. https://www.doi.org/10.1007/978-0-387-84831-0_6http:// www.worldbank.org/

7. The phenomenon of rising prices and the high cost of living in the Gaza Strip during the period 31/10/2007 - 12/6. The Palestinian National Information Center.

8. Gishah (2009) Under the Red Line destruction of infrastructure in Gaza. Gisha Center for Freedom of Movement.

9. Trapped humanitarian impact of two years of blockade on the Gaza Strip. The United Nations Office for the Coordination occupied Palestinian territories of Humanitarian Affairs. Special report.

10. The wall between the anvil and the humanitarian impact of Israeli restrictions on access to land and sea in the Gaza Strip. The United Nations Office for the Coordination occupied Palestinian territories of Humanitarian Affairs The World Food Programmed.

11. The Palestinian Center for Human Rights. A report on the impact of the closure on agricultural exports policy in the Gaza Strip

12. http://dx.doi.org/10.1080/02652030601053121PMA\%20site.\%20The \%20cumulative\%20data.\%20http:/www.pma.ps/

13. Report on UNCTAD's assistance to the Palestinian people: Developments in the economy of the occupied Palestinian territory. United Nations Conference on Trade and Development. Fifty-ninth Session.

14. Farouk Dawas (2001) The effects of collective punishment on the Palestinian economic infrastructure. Journal of Vision.
15. The Palestinian Central Bureau of Statistics. The performance of the Palestinian economy.

16. Raed Helles (2013) Local resources and ways of funding gap in the Palestinian economy. Unpublished Master Thesis.

17. Report on UNCTAD's assistance to the Palestinian people: Developments in the economy of the occupied Palestinian territory. United Nations Conference on Trade and Development.

18. Salman Alderaoe (2014) Palestinian economic relations and the factors influencing its development in light of regional and international variables. Journal of the University of Palestine Research and Studies.

19. The Palestinian economy: macroeconomic and trade policies in light of the occupation. United Nations Conference on Trade and Development.

20. Report on UNCTAD's assistance to the Palestinian people: Developments in the economy of the occupied Palestinian territory. United Nations Conference on Trade and Development.

21. Mazen Al-Egla (2014) A report on developments in the reconstruction of the Gaza Strip. Palestinian Planning Center Magazine.

22. Report on UNCTAD's assistance to the Palestinian people: Developments in the economy of the occupied Palestinian territory. United Nations Conference on Trade and Development.

23. Life segmented overview of the humanitarian situation in 2015. The Office for the Coordination of Humanitarian Affairs occupied Palestinian territory.

24. Abdel-Fattah Nasrallah (2003) Palestinian Foreign Trade Analysis of cash and vision. Studies and Planning Department.

25. The Palestinian Central Bureau of Statistics. The Palestinian labor force survey Annual Report.

26. Wafiq Aga, Samir Abu-Mdallah (2011) Tunnels in the Gaza Strip's economy: a national necessity Or economic and social disaster. Al-Azhar University in Gaza.

27. Salah Al-Awda, Rizk Alsaed Ahmed (2008) A study entitled infrastructure of the Palestinian economy.

28. Ease the blockade of humanitarian impact assessment on the population in the "Gaza Strip". The Coordinating Bureau of the occupied Palestinian territories of Humanitarian Affairs.

29. Mazen Al-Egla, Eman Al-Khodary (2016) Youth unemployment in the Gaza Strip: its development- characteristics solutions strategy readings. Palestinian Planning Center.

30. (1998) The poverty in the Palestinian territories. Palestinian Central Bureau of Statistics.

31. Rima Nazzal (2008) The new case of Ghazzawi and the Palestinian women. Journal of Tolerance.

32. Hidaya Simeon, et al. (2009) Research on the prioritization of women's issues in the Gaza Strip. Center for Women's Affairs.

33. Heba Azayan (2012) Summary worksheet:The impact of the siege of the Gaza Strip on the political participation of women, Introduction: Conference "blockade of the Gaza Strip: the assessment of impacts and coping strategies". Pal Think for Strategic Studies Gaza-Palestine.

34. Samir Abu Mdallah (2014) The effects of the blockade and the division of economic and social composition of the Gaza Strip on the Palestinian collective national project. Journal of the Faculty of Arts

35. Ministry of Health website.

36. Khaled Safi (2012) A summary worksheet: "The impact of the siege of the Gaza Strip on the Palestinian higher education sector." Introduction: Conference "blockade of the Gaza Strip: the assessment of impacts and coping strategies". Pal Think for Strategic Studies.

37. The performance of the Palestinian economy. The Palestinian Central Bureau of Statistics

38. The poverty in the Palestinian territories report the main results for the years 2009-2010. The Palestinian Central Bureau of Statistics.

39. The Palestinian Central Bureau of Statistics site. Statistics. 